\title{
A systematic review of qualitative literature on antimicrobial stewardship in Sub-Saharan Africa
}

George James Porter ${ }^{1 *}$, Stephen Owens ${ }^{2,3}$ and Matthew Breckons ${ }^{3}$

\begin{abstract}
Background: Antibiotic resistance is a major problem in every region of the globe and Sub-Saharan Africa (SSA) is no exception. Several systematic reviews have addressed the prevalence of resistant organisms but few have examined the underlying causes in this region. This systematic review of qualitative literature aims to highlight barriers and facilitators to antimicrobial stewardship in SSA.

Methods: A literature search of Embase and MEDLINE(R) was carried out. Studies were included if they were in English, conducted in SSA, and reported qualitative data on the barriers and facilitators of antimicrobial stewardship or on attitudes towards resistance promoting behaviours. Studies were screened with a simple critical appraisal tool. Secondary constructs were extracted and coded into concepts, which were then reviewed and grouped into themes in light of the complete dataset.

Results: The literature search yielded 169 results, of which 14 studies from 11 countries were included in the final analysis. No studies were excluded as a result of the critical appraisal. Eight concepts emerged from initial coding, which were consolidated into five major themes: ineffective regulation, health system factors, clinical governance, patient factors and lack of resources. The ineffective regulation theme highlighted the balance between tightening drugstore regulation, reducing over-the-counter sale of antibiotics, and maintaining access to medicines for rural communities. Meanwhile, health system factors explored the tension between antimicrobial stewardship and the need of pharmacy workers to maintain profitable businesses. Additionally, a lack of resources, actions by patients and the day-to-day challenges of providing healthcare were shown to directly impede antimicrobial stewardship and exacerbate other factors which promote resistance.
\end{abstract}

Conclusion: Antibiotic resistance in SSA is a multi-faceted issue and while limited resources contribute to the problem they should be viewed in the context of other factors. We identify several contextual factors that affect resistance and stewardship that should be considered by policy makers when planning interventions. This literature base is also incomplete, with only 11 nations accounted for and many studies being confined to regions within countries, so more research is needed. Specifically, further studies on implementing stewardship interventions, successful or not, would be beneficial to inform future efforts.

Keywords: Sub-Saharan Africa, Antibiotic resistance, Antibiotic stewardship, Public health, Global health, Qualitative synthesis

\footnotetext{
*Correspondence: g.porter2@newcastle.ac.uk

${ }^{1}$ Faculty of Medical Sciences, Newcastle University, Framlington Place, Newcastle Upon Tyne, UK

Full list of author information is available at the end of the article
} original author(s) and the source, provide a link to the Creative Commons licence, and indicate if changes were made. The images or other third party material in this article are included in the article's Creative Commons licence, unless indicated otherwise in a credit line to the material. If material is not included in the article's Creative Commons licence and your intended use is not permitted by statutory regulation or exceeds the permitted use, you will need to obtain permission directly from the copyright holder. To view a copy of this licence, visit http://creativecommons.org/licenses/by/4.0/. 


\section{Background}

According to The World Health Organisation (WHO), Antimicrobial resistance (AMR) directly threatens frontline clinical care, limiting our ability to treat infections as well as increasing the risks of interventions such as surgery and chemotherapy [1]. AMR also limits development by draining the global economy and reducing productivity due to sickness [1]. While considerable research is dedicated to the epidemiology of resistant organisms and novel therapeutics, another important facet is the clinical and behavioural factors driving resistance [2,3].

AMR is a growing problem in Sub-Saharan Africa (SSA) and is complicated by a lack of data [4]. One systematic review analysing resistance prevalence in Africa found that there was no data for $40 \%$ of African countries [4]. This is partly due to a paucity in quality-assured microbiology laboratories in the region, along with AMR being a low priority compared to other public health concerns $[5,6]$. Furthermore, according to Essack et al. [7], only $4.3 \%$ of countries in the WHO Africa region have national AMR plans while 14.9\% have national infection prevention and control policies.

The data that are available demonstrates a significant problem. One systematic review found that $E$. coli isolates had a median resistance of $88.1 \%$ to amoxicillin and $80.7 \%$ to trimethoprim, while $34 \%$ of $H$. influenzae isolates were resistant to amoxicillin [4]. There is also considerable resistance to WHO-recommended first-line drugs [8]. The WHO-recommended treatment for sepsis in children under 2 months of age is ampicillin and gentamicin [8]. According to systematic review data, the median non-susceptibility rate of Klebsiella isolates from paediatric infections in SSA was 100\% (IQR 71-100) for ampicillin and 49\% (IQR 48-58) for gentamicin [8]. Additionally, the WHO acknowledge that in many developing countries illnesses such as pneumonia and dysentery can no longer be treated with first-line medications [1]. Without prompt action these trends will likely worsen and countries with stretched health resources, whose patients cannot afford the required second or third-line antibiotics, will be disproportionately affected.

There is considerable research dedicated to combatting AMR, especially in resource-limited settings $[1,5]$. The behaviours which drive resistance are thus relatively well defined [5]. Within SSA there are many examples of cross-sectional surveys of the prevalence of these behaviours, which include patient self-medication, overthe-counter (OTC) sales of prescription-only antibiotics and over-prescribing of antibiotics $[9,10]$. While these surveys identify what behaviours cause resistance it is also important to identify the underlying drivers of these behaviours. A qualitative approach can provide rich data from patients, healthcare staff and public health professionals describing why resistance-promoting behaviours happen. These data are of value to policymakers; highlighting key determinants and context of antibiotic resistance.

Systematic review and synthesis of qualitative data is a reasonably new methodology but one that has gained acceptance in scientific literature. Indeed, the Cochrane collaboration recently called reviews of qualitative evidence a "new milestone for Cochrane" [11]. There are many methods of qualitative synthesis, each having evolved from different fields [12,13]. There is little consensus on the best method, with each having their own strengths and weaknesses [12]. Studies must therefore be designed based on the questions they intend to answer $[12,13]$.

There have been significant efforts to research barriers and facilitators to antimicrobial stewardship (AMS) in Sub-Saharan Africa, but to our knowledge no synthesis of qualitative literature has yet been published on the subject. The objective of this review is to highlight barriers and facilitators to antimicrobial stewardship and sociocultural factors driving antimicrobial resistancepromoting behaviour in patients and healthcare staff in Sub-Saharan Africa. We hope that this will provide policymakers with a more comprehensive view of the underlying factors which need to be addressed to curb AMR in this region and highlight gaps in the literature.

\section{Methods}

\section{Research methodology}

The methodology for this review was guided by the Preferred Reporting Items for Systematic Reviews and Meta-analyses (PRISMA) guidelines and checklist [14]. Selection of methodology was guided by the review written by Bearman and Dawson [13]. Specific information on how to extract, code and analyse qualitative themes was sourced from Butler et al. and Seers [15, 16]. Given that we are attempting to summarise current literature and identify key recurrent messages, thematic analysis was selected as our method of qualitative synthesis [13].

For the purposes of this review, the United Nations Development Programme's definition of Sub Saharan Africa was used to define geographical inclusion [17].

\section{Search strategy and selection criteria}

Ovid online was used to search Embase and Ovid $\operatorname{MEDLINE}(\mathrm{R})$. There were no restrictions with respect to date of publication. Results were limited to publications in English. The last search occurred on 19/05/2020. Multiple searches were conducted, used terms included 'Antibiotic Resistance' or 'Antimicrobial Stewardship' along with "Africa South of the Sahara" and 'Qualitative Research'. All terms were exploded and then combined 
with the Boolean operator AND. Medical subject headings (MeSH) terms were also included. The full search strategy for Embase and MEDLINE(R) can be found in "Appendices 1 and 2", respectively.

The authors also searched for cross-sectional surveys, as some of these studies had qualitative elements to them. This was done systematically via similar keywords to above but substituting 'qualitative research' for 'cross-sectional survey'. The references of included studies were also searched for additional papers. Studies first underwent abstract screening to ensure they met the inclusion criteria and then full-text screening and data extraction (Table 1).

\section{Critical appraisal}

Critical appraisal was conducted by GJP. All included studies were evaluated using the CASP (Critical Appraisal Skills Programme) qualitative research appraisal tool, a 10 -item checklist covering domains including research design, data collection and analysis [18]. The first 9 are answered 'yes', 'no' or 'can't tell' and the remaining question asks for a subjective evaluation of the value of the study [18]. Studies were scored principally by the first author. The first three CASP questions provide a screening tool to evaluate if the research question of the study can or should be assessed via qualitative methodology. Failure on this section would result in exclusion of the study. Meanwhile, the latter questions were the taken into account when resolving disagreements between studies.

\section{Data extraction and synthesis}

Data were defined as secondary constructs, that is to say the researcher's interpretations and conclusions, rather than direct quotes from study participants. Thematic analysis, as described by Seers and Bearman and Dawson, was then conducted $[13,16]$. The first author read each paper and coded secondary constructs, grouping them into various concepts. These concepts were then reviewed and simplified into themes once all studies had been coded. The final models were evaluated by senior authors $(\mathrm{SO}$ and $\mathrm{MB})$ to ensure they were consistent with the source material.

The summary measure of this review was refutational and reciprocal synthesis across studies about the barriers to AMS implementation and the causes of resistance-promoting behaviour. Other information collected included country of origin, the number and occupation of interviewees in the study and information about healthcare staff and patient's perceptions of AMR as a threat (Table 1).

\section{Results}

\section{Included studies}

Excluding duplicates, the literature search yielded 169 results, of which 138 were excluded on abstract screening. This resulted in 35 papers which underwent fulltext review and 14 papers included in final analysis. A PRSIMA flow diagram can be found in Fig. 1. Data were found relating to 11 of 46 SSA countries.

The average CASP score was $7.8 / 9$ and the lowest score was $7 / 9$. The most common omission was a lack of discussion of the relationship between researchers and participants, which occurred in 5 of the 11 studies. Additionally, 4 studies either did not explicitly detail recruitment strategy or used either subjective or selective recruitment criteria. Table 2 illustrates the results of the critical appraisal.

Eight concepts emerged upon the first round of coding, which were condensed into 5 main themes: ineffective regulation, healthcare system factors, clinical governance, patient factors and lack of resources. The original concepts can be found in "Appendix 3".

\section{Ineffective regulation}

This theme describes a lack of regulation at country or region-level of resistance-promoting behaviours. Torres et al. noted that while there are laws against OTC sale of antibiotics in Mozambique these were rarely enforced [19]. Moreover, all pharmacy workers

Table 1 The inclusion criteria used in the original literature search and screening process and their explanations

\begin{tabular}{|c|c|}
\hline Inclusion criteria & Explanation \\
\hline 1. Must be a qualitative study & $\begin{array}{l}\text { This includes in-depth interviews, focus groups, ethnography and other qualitative techniques } \\
\text { It does not include cross-sectional surveys, surveillance data or clinical trials unless they contain a qualitative } \\
\text { component as listed above }\end{array}$ \\
\hline $\begin{array}{l}\text { 2. Must pertain, at least in part, to data } \\
\text { gathered in Sub-Saharan Africa }\end{array}$ & $\begin{array}{l}\text { This allows multi-country studies, in which case the secondary constructs from SSA nations only were } \\
\text { extracted } \\
\text { SSA was defined as per the United Nations Development Programme [13] }\end{array}$ \\
\hline $\begin{array}{l}\text { 3. Must be directly relating to causes of } \\
\text { resistance-promoting behaviours }\end{array}$ & $\begin{array}{l}\text { This includes barriers/facilitators to implementation of stewardship schemes and social and cultural determi- } \\
\text { nants of resistance-promoting behaviours } \\
\text { It does not include discussions exclusive to HIV or Malaria, as these were seen as separate issues with different } \\
\text { socio-cultural context }\end{array}$ \\
\hline 4. Reporting primary research findings & This excludes review articles \\
\hline
\end{tabular}




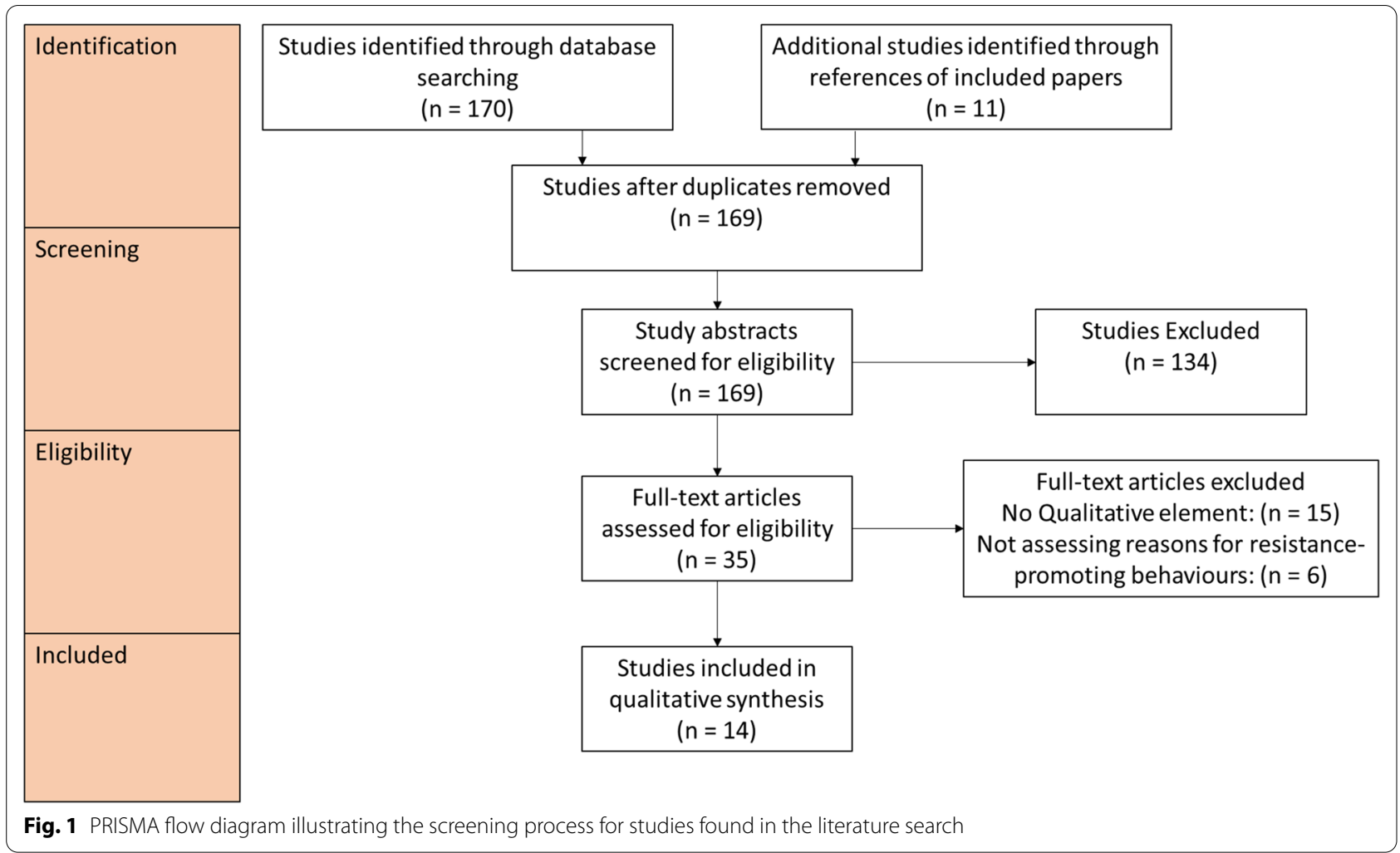

interviewed in Addis Ababa by Gebretekle et al. [20] mentioned that the weak or non-existent enforcement of regulation was a major driver of inappropriate dispensing.

There is an apparent tension between medicines access and regulation. This was highlighted by Charani et al. [21], stating that while tightening regulations would probably lower the rate of OTC antibiotic sales it could also reduce access to medications if drug sellers were shut down. This is supported by Yantzi et al. [22], who added that more remote communities, who could often not afford to travel to a clinic to obtain a prescription, would be disproportionately affected by this.

\section{Healthcare system factors}

This theme relates to the nature of the healthcare systems in SSA encouraging resistance-promoting behaviours. It was sub-divided into health system heterogeneity and pharmacies as a business.

\section{Health system heterogeneity}

Healthcare professionals interviewed in Burkina Faso stated that patients often saw a combination of local healers, pharmacists, private and public healthcare services regularly [21]. This system allows patients to 'shop around' for a service that will provide antibiotics [21]. It also limits a clinician's ability to obtain an accurate drug history, making it challenging to prescribe an antibiotic the patient has not recently received [21]. Complex healthcare systems are also harder to regulate, with some authors noting that this is further complicated by the black market and more targeted medication sellers such as 'pension markets', which are aimed at older adults $[21,23]$.

\section{Pharmacies as a business}

Interviews of drug store customers in Dar es Salaam indicated that if a pharmacy refused to sell antibiotics then customers would simply go to another [24]. Pharmacy workers interviewed by Gebretekle et al. [20] reinforced this, adding that pharmacy owners would reprimand or dismiss workers who refused sales on the grounds of stewardship. Equally, while many pharmacy customers in Blantyre felt that it was reasonable to be denied antibiotics unless they had a prescription, many also argued that pharmacies were primarily businesses and thus should never refuse sales [25]. This was also highlighted by Dillip et al. [26]. They found that even among Tanzanian accredited drug dispensing outlets, which are certified to follow national dispensing guidelines, inappropriate antibiotic dispensing was common due to the need for profit and the fear that customers would simply go elsewhere [26]. 


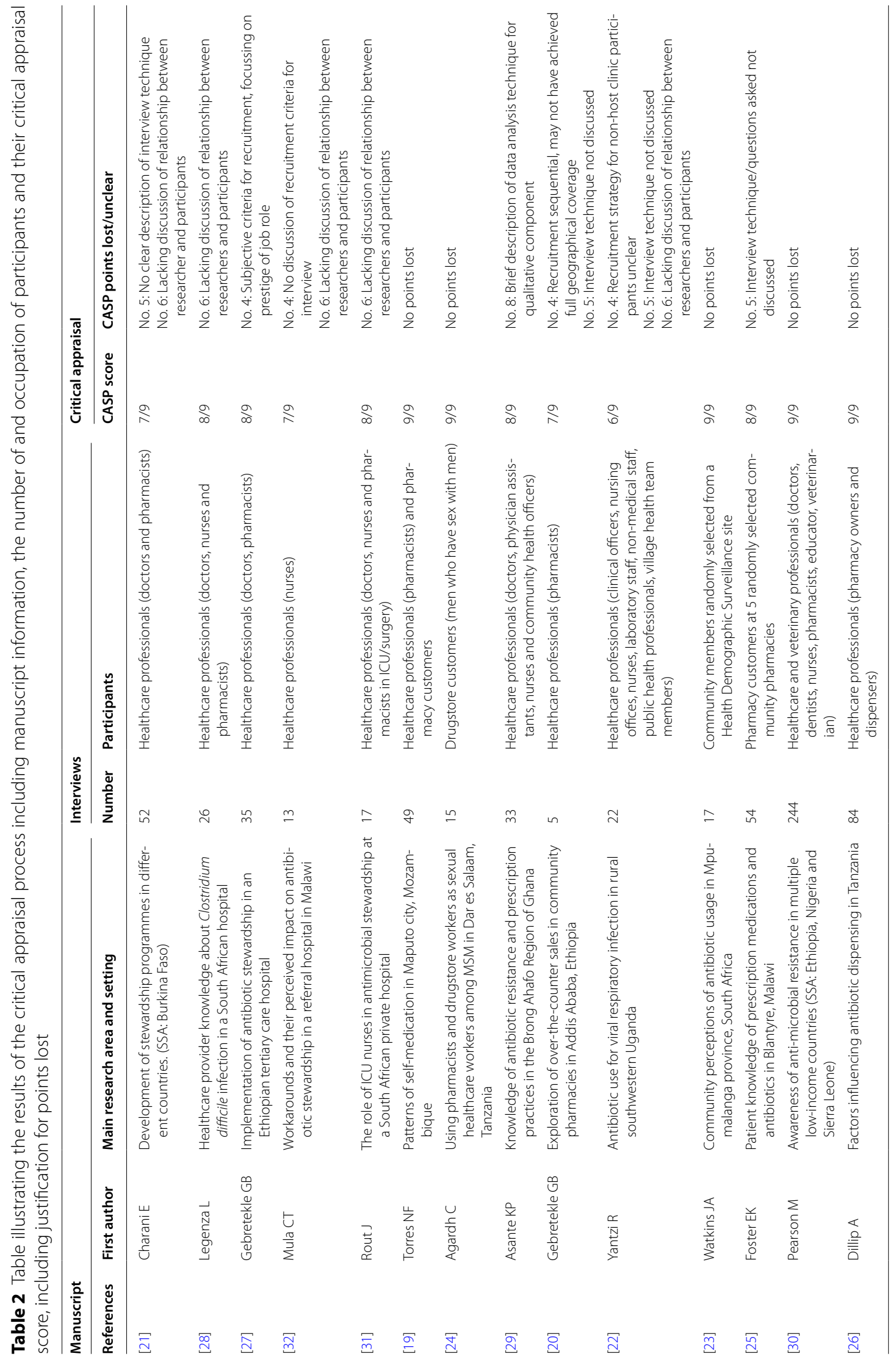




\section{Clinical governance}

This theme relates to lack of AMS guidelines or lack of adherence to them. Gebretekle et al. [27] found that a major barrier to implementation of AMS programmes in an Ethiopian tertiary care hospital was a lack of support for AMS policy at institutional and national level. Furthermore many junior physicians routinely prescribed "safe" broad-spectrum antibiotics out of fear of receiving a negative career evaluation if they used a narrow-spectrum one [27]. This was echoed by physicians in surgical wards who would prolong the use of pre and post-operative antibiotics to prevent infectious complications which they would be blamed for [27].

In Legenza et al.s [28] study in South Africa only 30\% of clinicians knew about $C$. difficile guidelines, with even fewer being able to correctly recall them. Furthermore, many healthcare professionals interviewed in Ghana repeatedly prescribed antibiotics based on personal preference and experience rather than referring to guidelines [29]. This was also true of prescribers interviewed by Pearson and Chandler and Yantzi et al. [22, 30]. Additionally it was apparent that affordability and physical availability of antibiotics often dictated prescriptions more than guidelines [30]. Finally Yantzi et al. [22] added that prescribing a drug is often considered synonymous with a high standard of care by patients; adding to the pressure on clinicians to ignore stewardship guidelines. Adherence to guidelines was also examined by Rout and Brysiewicz [31], who argue that members of staff specifically trained to safeguard stewardship could help alleviate some of these problems.

Five papers in our study assessed the knowledge level of healthcare staff and they found that AMR is generally perceived as a significant threat, although this did not always translate into practice $[21,26,27,29,30]$. Pharmacy workers interviewed by Dillip et al. [26] in Tanzania could all correctly recite national antibiotic prescribing guidelines but all also admitted to ignoring these guidelines. Furthermore Gebretekle et al. [27] found that $90 \%$ of interviewed physicians recognised AMR as a national threat but more than half could not identify what organisms commonly caused resistant infections in their region.

\section{Patient factors}

This theme refers to actions by patients which encouraged resistance-promoting behaviour by healthcare professionals such as inappropriate dispensing of antibiotics.

It was commonly reported that patients recognised and remembered certain drugs and the symptoms they were prescribed for. This allowed them to demand antibiotics from the pharmacist directly, rather than attend a clinic or hospital first which was perceived by patients as a waste of time and/or money. This was a dominant theme in Torres et al's [19] study in Mozambique. Many of the patients in this study knew the exact name and dose of drug they wanted [19]. Similar patterns were illustrated in all four of the included studies that interviewed patients [19, 23-25].

Another paradigm explored by Agardh et al. [24] was that marginalised communities, such as men who have sex with men (MSM), may prefer to only visit pharmacies. This is because pharmacies require less information about their personal lives and are in less public places, reducing the chance of encountering members of their community who may enquire why they are receiving medication [24].

\section{Lack of resources}

This theme constituted a lack of the facilities required to appropriately prescribe antibiotics and overstretched health services necessitating practices that promote resistance. It was an over-arching theme that appeared in several of the other themes.

Four studies mentioned that a lack of laboratory facilities prevented antibiotic prescribing based on sensitivity testing [27-30]. Without sensitivity information clinicians must rely on resistance-fostering broad-spectrum antibiotics. Moreover, Legenza et al. [28] found that limited clinician time and a lack of IT infrastructure meant that often only the available cultures perceived as "more important" are checked.

The issue of limited ward time was echoed by Mula et al. [32] who studied 'workarounds': short-cuts taken on wards to reduce the time spent on certain tasks. Relevant examples include issuing rounded-up doses or simplified regimens that patients are more likely to understand and take less time to explain [32]. While these are arguably necessary due to the significant shortfall in healthcare staff, they also contribute to AMR.

The aforementioned problem of patients going straight to pharmacies also has roots in the lack of healthcare resources. Long wait-times at clinics, principally due to inadequate staffing, make skipping them an attractive option [20, 22]. Equally many healthcare facilities in SSA have a very limited range of available antibiotics, resulting in patients being prescribed the same antibiotic on every encounter [19]. This increases the likelihood of patients remembering the drug name and dose and, in combination with the internet, is a major driver of OTC sales according to Torres et al. [19]. 


\section{Discussion}

\section{Key findings}

To our knowledge this is the first systematic synthesis of qualitative studies surrounding antibiotic resistance in SSA. Studies were found for 11 out of the 46 SSA countries, and this lack of coverage is in keeping with findings from systematic reviews of surveillance data [4]. Additionally, many of the issues identified are either due to or exacerbated by the lack of resources in the study countries. Indeed, one could argue that healthcare system heterogeneity as a whole is a symptom of under-resourced healthcare.

Lack of resources is not solely responsible for AMR in SSA and several contextual factors were repeated throughout the included studies. There was consensus that a tension existed between a pharmacy worker's role in upholding antimicrobial stewardship and the need for profit in a highly competitive economy. There was also conflict between the need for regulation of drug stores and the risk of limiting access to medications. Several studies highlighted the fact that many patients see going to a clinic as expensive and time-consuming when they can simply demand OTC sale direct from the dispensary. It is also apparent that despite ongoing efforts to educate staff about antimicrobial stewardship, resistance-promoting behaviours still occur in clinics and hospitals for a variety of reasons.

\section{Comparison with existing literature}

Our findings have much in common with a 2016 review of the implementation challenges of global antimicrobial stewardship by Tiong et al. [33]. They argue that while there is a lack of resources, many stewardship interventions themselves are categorically at odds with developing economies [33]. Specifically, they cite the balance between regulation and access to medications as an example of this disconnect between policy and practice [33]. We also agree with Van Dijick et al. [34], who state that the literature base surrounding stewardship interventions is heterogenous and complicated by a myriad of sociocultural paradigms unique to each country within SSA. Furthermore our main themes bear considerable resemblance to the findings of Kpokiri et al. and Huttner et al., who published studies analysing the implementation of antimicrobial stewardship programmes in Nigeria and across the globe, respectively $[35,36]$. In particular, we share their sentiment that further publication of evaluation of stewardship interventions, regardless of their success, is exceedingly valuable to inform future efforts.

When comparing literature it should be noted that the health systems of SSA are far from identical. One example is that in one study in Ethiopia all interviewed pharmacy workers either held a bachelor's degree in pharmacy (B. Pharm) or a diploma in pharmacy [20]. Meanwhile in Tanzania the level of qualification of pharmacy worker depends on the type of pharmacy and can range from a degree-level pharmacist to any individual with a medical background, such as a nurse [24]. Furthermore, the development and enforcement of antibiotic prescribing guidelines varies greatly between different countries in SSA, and few countries have a national AMR policy $[7,37]$. These differences reinforce the need to tailor stewardship interventions to individual countries.

Patient education, while out of the scope of this review, should also be considered when evaluating our findings. Torres et al. conducted a systematic scoping review of factors influencing self-medication with antibiotics in low and middle income countries [38]. They found that patients who possessed low or very high knowledge of antibiotics were the most likely to engage in self-medication [38]. Some of the papers in our study also discussed this, with Gebretekle et al. finding that those with specific knowledge on antibiotics were better equipped to specifically request them while Watkins et al. reported that very few patient interviewees knew of AMR as an issue [20,23]. While it has a small literature base, patient education impacts resistance-promoting behaviours and thus should be included both in future interventions and research efforts.

Intertwined with patient education on AMR is general health literacy [39-41]. This also varies among SSA countries, though there is little data in this field [39-41]. One study of 224,751 individuals from 14 SSA countries found an average prevalence of high health literacy of $37.55 \%$ and a range of $8.93 \%$ (Niger) to $63.89 \%$ (Namibia) [39]. A systematic review by Castro-Sánchez et al. [41] suggests that there is a relationship between health literacy and antibiotic usage, but it is complex and as yet not fully understood. Furthermore, this relationship does not appear to have been studied in SSA outside of South Africa [41]. Health literacy is therefore likely another important contextual factor in stewardship in need of further research.

While the included literature showed reasonable consensus on the levels of knowledge of AMR among staff, this is not replicated in wider literature. Labi et al. found that $8.9 \%(14 / 157)$ physicians in a Ghanaian tertiary care hospital considered AMR a threat locally, while Erku reports that $26.5 \%$ of 449 community pharmacists interviewed in Ethiopia believed that stewardship should be practised by drug stores [42, 43]. Studies from both Ghana and Ethiopia in this review found that more than half of the healthcare staff interviewed at least acknowledged AMR as a threat $[27,29]$. This reinforces the fact that this literature base is far from complete and more data is required. 


\section{Limitations}

This study has a number of limitations. The literature search was conducted in English meaning that manuscripts in other languages could have been missed. While translated papers were found and included in the abstract screening, none met the inclusion criteria. Equally, the lack of geographical coverage constitutes a reporting bias, as countries where AMR is considered a less important issue are less likely to commission research into it. We did not include articles specifically on veterinary practice, another important source of AMR [44]. Finally, there is the potential for publication bias. African nationals underrepresented in academia, and may find it more difficult to publish papers in major journals due to a lack of resources or a lack of interest on the part of the journals [45].

\section{Conclusion}

Antibiotic resistance is a growing problem and could significantly undermine healthcare in SSA. Lack of data is a major barrier to any public health interventions in this field. Therefore, wider surveillance and reporting of resistant infections along with further research into its underlying drivers are needed. Specifically, research in countries which are not currently included in the literature base should be prioritised. Moreover, funding, publication and evaluation of stewardship interventions, successful or not, could help inform future endeavours and inspire action among policy-makers. It is important to recognise that stewardship and resistance do not exist in isolation and are part of wider healthcare systems. Increased regulation seems an obvious course of action but must be balanced with continuing access to medications. Financial incentives to drug stores that comply with regulation, rather than closing those than do not, could be an acceptable middle ground in this regard. Equally, increased national and regional support for stewardship could improve its priority in a clinical setting. In summary, while increased health resources will help AMS efforts in SSA, specific interventions tailored to the unique context of the region, are also required.

\section{Appendix 1: Search strategy for embase}

\begin{tabular}{ll}
\hline Search term & Number of results \\
\hline Qualitative research/ & 71,954 \\
$\begin{array}{l}\text { Antimicrobial stewardship.mp. or exp antimicrobial } \\
\quad \text { stewardship/ }\end{array}$ & 6749 \\
Exp "Africa south of the Sahara"/ & 223,132 \\
1 and 2 and 3 & 8 \\
\hline
\end{tabular}

\begin{tabular}{ll}
\hline Search term & Number of results \\
\hline $\begin{array}{l}\text { Antibiotic resistance.mp. or exp antibiotic resist- } \\
\text { ance/ }\end{array}$ & 162,413 \\
Exp "Africa south of the Sahara"/ & 223,123 \\
Qualitative research.mp. or exp qualitative research/ & 82,173 \\
1 and 2 and 3 & 11 \\
\hline
\end{tabular}

\begin{tabular}{ll}
\hline Search term & Number of results \\
\hline $\begin{array}{l}\text { Exp antimicrobial stewardship/ or exp antibiotic } \\
\text { resistance/ }\end{array}$ & 154,784 \\
Exp "Africa south of the Sahara"/ & 223,435 \\
Survey.mp & $1,095,152$ \\
Cross-sectional study.mp. or exp cross-sectional & 373,722 \\
study/ & \\
1 and 2 and 3 and 4 & 42 \\
\hline
\end{tabular}

\begin{tabular}{ll}
\hline Search term & Number of results \\
\hline $\begin{array}{l}\text { Cross-sectional survey.mp. or exp cross-sectional } \\
\text { studies/ }\end{array}$ & 328,594 \\
Exp "Africa South of the Sahara"/ & 203,956 \\
Exp antimicrobial stewardship/ & 1183 \\
1 and 2 and 3 & 2 \\
\hline
\end{tabular}

\begin{tabular}{ll}
\hline Search term & Number of results \\
\hline Exp "Africa South of the Sahara" & 203,956 \\
Antibiotic resistance.mp. or exp drug resistance, & 176,519 \\
$\quad$ microbial/ & \\
Survey.mp. or exp "Surveys and Questionnaires"/ & $1,320,095$ \\
1 and 2 and 3 and 4 & 93 \\
\hline
\end{tabular}
Appendix 2: Search Strategy for Ovid Medline(R)
and in-process and other non-indexed citationsw

\begin{tabular}{ll}
\hline Search term & Number of results \\
\hline $\begin{array}{l}\text { Antibiotic resistance.mp. or exp drug resistance, } \\
\text { microbial/ }\end{array}$ & 176,214 \\
Qualitative research.mp. or exp qualitative research/ & 63,788 \\
Exp "Africa South of the Sahara"/ & 203,519 \\
1 and 2 and 3 & 11 \\
\hline
\end{tabular}




\begin{tabular}{ll}
\hline Search term & Number of results \\
\hline $\begin{array}{l}\text { Antibiotic stewardship.mp. or exp antimicrobial } \\
\text { stewardship/ }\end{array}$ & 2703 \\
Qualitative research.mp. or exp qualitative research/ & 63,826 \\
Exp "Africa South of the Sahara"/ & 203,519 \\
1 and 2 and 3 & 3 \\
\hline
\end{tabular}

\section{Appendix 3: Original concepts}

These were the original thematic concepts identified by GJP and then validated and consolidated into themes by GJP and the co-authors in light of the fully coded papers.

\begin{tabular}{|c|c|c|}
\hline Theme & Explanation & $\begin{array}{l}\text { Papers expressing } \\
\text { theme }\end{array}$ \\
\hline Ineffective regulations & $\begin{array}{l}\text { This encompassed } \\
\text { comments from } \\
\text { several papers } \\
\text { about regulations } \\
\text { either being absent } \\
\text { or poorly enforced. } \\
\text { This allowed } \\
\text { patients to procure } \\
\text { prescription-only } \\
\text { medication such as } \\
\text { antibiotics without } \\
\text { a prescription. } \\
\text { Interestingly, several } \\
\text { studies argued } \\
\text { that rigid enforce- } \\
\text { ment of regulations } \\
\text { would cut off the } \\
\text { supply of medica- } \\
\text { tions to certain } \\
\text { communities who } \\
\text { found it difficult to } \\
\text { get a prescription in } \\
\text { the first place }\end{array}$ & [19-22] \\
\hline $\begin{array}{l}\text { Heterogeneity in } \\
\text { healthcare }\end{array}$ & $\begin{array}{l}\text { Many of the study } \\
\text { countries had very } \\
\text { heterogenous } \\
\text { healthcare systems, } \\
\text { with patients } \\
\text { seeing traditional } \\
\text { practitioners, private } \\
\text { clinics and govern- } \\
\text { ment healthcare. } \\
\text { This promoted } \\
\text { patients passing } \\
\text { through multiple } \\
\text { different healthcare } \\
\text { branches, taking } \\
\text { many medications } \\
\text { and not having } \\
\text { accurate medical } \\
\text { records available }\end{array}$ & [21] \\
\hline Black market supply & $\begin{array}{l}\text { Black market suppli- } \\
\text { ers were reported } \\
\text { specifically in } 2 \\
\text { papers. These are } \\
\text { hard to regulate and } \\
\text { increase illicit access } \\
\text { to prescription-only } \\
\text { medications }\end{array}$ & {$[21,23]$} \\
\hline
\end{tabular}

\begin{tabular}{|c|c|c|}
\hline Theme & Explanation & $\begin{array}{l}\text { Papers expressing } \\
\text { theme }\end{array}$ \\
\hline $\begin{array}{l}\text { Lack of resistance } \\
\text { reporting infrastruc- } \\
\text { ture }\end{array}$ & $\begin{array}{l}\text { This was reported } \\
\text { in five papers. This } \\
\text { encompassed a } \\
\text { lack of the culture } \\
\text { machines and/ } \\
\text { or laboratories } \\
\text { necessary for the } \\
\text { timely reporting of } \\
\text { sensitivity results. } \\
\text { This made it difficult } \\
\text { for clinicians to pre- } \\
\text { scribe appropriate } \\
\text { narrow-spectrum } \\
\text { antibiotics, relying } \\
\text { instead on broad- } \\
\text { spectrum ones } \\
\text { which are more } \\
\text { likely to foster resist- } \\
\text { ance }\end{array}$ & {$[27-30]$} \\
\hline $\begin{array}{l}\text { Bigger clinical con- } \\
\text { cerns }\end{array}$ & $\begin{array}{l}\text { This was reported } \\
\text { in three papers. In } \\
\text { many cases, issues } \\
\text { such as tuberculosis, } \\
\text { HIV and tropical } \\
\text { diseases formed } \\
\text { a much greater } \\
\text { concern on wards. } \\
\text { This meant that } \\
\text { little attention was } \\
\text { paid to resistant } \\
\text { organisms }\end{array}$ & {$[27,28]$} \\
\hline Clinical governance & $\begin{array}{l}\text { This was reported in } \\
\text { many papers, and } \\
\text { encompassed a lack } \\
\text { of appropriate stew- } \\
\text { ardship guidelines (or } \\
\text { a lack of adherence } \\
\text { to them) at the level } \\
\text { of individual wards } \\
\text { and pharmacies. } \\
\text { There were many } \\
\text { reasons for this, such } \\
\text { as lack of knowledge } \\
\text { by clinical staff or } \\
\text { fear that prescribing } \\
\text { a narrow-spectrum } \\
\text { antibiotic would } \\
\text { result in a negative } \\
\text { career validation. } \\
\text { It also involved } \\
\text { pharmacies needing } \\
\text { to make a profit, } \\
\text { and doing so by } \\
\text { selling prescription- } \\
\text { only medication to } \\
\text { patients without } \\
\text { appropriate prescrip- } \\
\text { tions }\end{array}$ & {$[19,20,22,24-31]$} \\
\hline
\end{tabular}




\begin{tabular}{|c|c|c|}
\hline Theme & Explanation & $\begin{array}{l}\text { Papers expressing } \\
\text { theme }\end{array}$ \\
\hline Lack of equipment & $\begin{array}{l}\text { This encompassed a } \\
\text { lack of resources at } \\
\text { the level of wards } \\
\text { and departments. } \\
\text { In some cases, this } \\
\text { resulted in only } \\
\text { having access to } \\
\text { a small number of } \\
\text { antibiotics, causing } \\
\text { patients to learn } \\
\text { their names and } \\
\text { increasing the ease } \\
\text { of which they were } \\
\text { procured. In other } \\
\text { cases it was a lack of } \\
\text { ward time to devote } \\
\text { to checking culture } \\
\text { results and altering } \\
\text { prescriptions }\end{array}$ & {$[22,28,31,32]$} \\
\hline Patient factors & $\begin{array}{l}\text { Another wide- } \\
\text { reaching theme, this } \\
\text { was specific patient } \\
\text { behaviours that } \\
\text { fostered antimicro- } \\
\text { bial resistance or } \\
\text { hampered efforts } \\
\text { for antimicrobial } \\
\text { stewardship. Some } \\
\text { examples included } \\
\text { patients 'shopping } \\
\text { around'for a health- } \\
\text { care service that } \\
\text { would sell them } \\
\text { antibiotics regard- } \\
\text { less of prescription, } \\
\text { self-medication, } \\
\text { or when patients } \\
\text { would learn the } \\
\text { dose and name } \\
\text { of an antibiotic so } \\
\text { they could directly } \\
\text { request it from a } \\
\text { pharmacist without } \\
\text { a prescription }\end{array}$ & {$[19,20,22-26,29]$} \\
\hline
\end{tabular}

\section{Abbreviations}

AMR: Antimicrobial resistance; CASP: Critical Appraisal Skills Programme; OTC: Over the counter; PRISMA: Preferred Reporting Items for Systematic Reviews and Meta Analyses; SSA: Sub-Saharan Africa; WHO: World Health Organization.

\section{Authors' contributions}

GJP was the primary author and conducted the literature search, critical appraisal and thematic analysis of the papers in consultation with SO and MB. SO helped plan the study, conduct the literature search and write the text while $\mathrm{MB}$ provided guidance in analysis of qualitative literature and made substantial changes to the text itself. All authors read and approved the final manuscript.

\section{Funding}

No funding was received for this work.

\section{Availability of data and materials}

All papers included in this review are available in the 'References'section. A full search strategy, along with the original thematic analysis spreadsheet, is available from the corresponding author on request.

\section{Declarations}

Ethics approval and consent to participate

Not applicable.

\section{Consent for publication}

Not applicable.

\section{Competing interests}

The authors declare that they have no competing interests.

\section{Author details}

${ }^{1}$ Faculty of Medical Sciences, Newcastle University, Framlington Place, Newcastle Upon Tyne, UK. ${ }^{2}$ Department of Paediatric Immunology and Infectious Diseases, Great North Children's Hospital, Newcastle Upon Tyne Hospitals NHS Foundation Trust, Newcastle upon Tyne, UK. ${ }^{3}$ Population Health Sciences Institute, Newcastle University, Framlington Place, Newcastle Upon Tyne, UK.

Received: 4 September 2020 Accepted: 28 June 2021

Published online: 20 August 2021

\section{References}

1. World Health Organization. Global action plan on antimicrobial resistance. Geneva; 2015.

2. Levy SB, Marshall B. Antibacterial resistance worldwide: causes, challenges and responses. Nat Med. 2004;10(12):S122-9.

3. Sahoo KC, Tamhankar AJ, Johansson E, Lundborg CS. Antibiotic use, resistance development and environmental factors: a qualitative study among healthcare professionals in Orissa, India. BMC Public Health. 2010;10(1):629.

4. Tadesse BT, Ashley EA, Ongarello S, Havumaki J, Wijegoonewardena M, González IJ, et al. Antimicrobial resistance in Africa: a systematic review. BMC Infect Dis. 2017;17(1):616.

5. Laxminarayan R, Duse A, Wattal C, Zaidi AKM, Wertheim HFL, Sumpradit N, et al. Antibiotic resistance - the need for global solutions. Lancet Infect Dis. 2013;13(12):1057-98.

6. Leopold SJ, van Leth F, Tarekegn H, Schultsz C. Antimicrobial drug resistance among clinically relevant bacterial isolates in sub-Saharan Africa: a systematic review. J Antimicrob Chemother. 2014;69(9):2337-53.

7. Essack SY, Desta AT, Abotsi RE, Agoba EE. Antimicrobial resistance in the WHO African region: current status and roadmap for action. J Public Health. 2016:39(1):8-13.

8. Williams PCM, Isaacs D, Berkley JA. Antimicrobial resistance among children in sub-Saharan Africa. Lancet Infect Dis. 2018;18(2):e33-44.

9. Thriemer K, Katuala Y, Batoko B, Alworonga J-P, Devlieger H, Van Geet C, et al. Antibiotic prescribing in DR Congo: a knowledge, attitude and practice survey among medical doctors and students. PLoS ONE. 2013;8(2):e55495-e.

10. Owour l, Alwar J, Oyugi H. Perceptions influencing self medication with antibiotics and/or antimalarials among the households in Nyalenda B sub-location, Kisumu County, Kenya. Am J Public Health Res. 2015;3(3):116-21.

11. Gülmezoglu AM, Chandler J, Shepperd S, Pantoja T. Reviews of qualitative evidence: a new milestone for Cochrane. Cochrane Database Syst Rev. 2013;11:ED000073.

12. Barnett-Page $E$, Thomas J. Methods for the synthesis of qualitative research: a critical review. BMC Med Res Methodol. 2009;9(1):59.

13. Bearman M, Dawson P. Qualitative synthesis and systematic review in health professions education. Med Educ. 2013:47(3):252-60.

14. Moher D, Liberati A, Tetzlaff J, Altman DG, The PG. Preferred reporting items for systematic reviews and meta-analyses: the PRISMA statement. PLoS Med. 2009;6(7):e1000097.

15. Butler A, Hall H, Copnell B. A guide to writing a qualitative systematic review protocol to enhance evidence-based practice in nursing and health care. Worldviews Evid-Based Nurs. 2016;13(3):241-9.

16. Seers K. Qualitative systematic reviews: their importance for our understanding of research relevant to pain. Br J Pain. 2015;9(1):36-40.

17. United Nations Development Programme. About Sub-Saharan Africa. https:// www.africa.undp.org/content/rba/en/home/regioninfo.html. 
18. Critical Appraisal Skills Programme. CASP Qualitative Checklist; 2018. https:// casp-uk.net/wp-content/uploads/2018/01/CASP-Qualitative-Checklist-2018. pdf.

19. Torres NF, Solomon VP, Middleton LE. Patterns of self-medication with antibiotics in Maputo City: a qualitative study. Antimicrob Resist Infect Control. 2019;8(1):161.

20. Gebretekle GB, Serbessa MK. Exploration of over the counter sales of antibiotics in community pharmacies of Addis Ababa, Ethiopia: pharmacy professionals' perspective. Antimicrob Resist Infect Control. 2016:5:2.

21. Charani E, Smith I, Skodvin B, Perozziello A, Lucet JC, Lescure FX, et al. Investigating the cultural and contextual determinants of antimicrobial stewardship programmes across low-, middle- and high-income countries-A qualitative study. PLoS ONE. 2019;14(1):e0209847.

22. Yantzi R, van de Walle G, Lin J. "The disease isn't listening to the drug": the socio-cultural context of antibiotic use for viral respiratory infections in rural Uganda. Glob Public Health. 2019;14(5):750-63.

23. Anstey Watkins J, Wagner F, Xavier Gómez-Olivé F, Wertheim H, Sankoh O, Kinsman J. Rural South African community perceptions of antibiotic access and use: qualitative evidence from a health and demographic surveillance system site. Am J Trop Med Hyg. 2019;100(6):1378-90.

24. Agardh C, Weije F, Agardh A, Nyoni J, Ross MW, Kashiha J, et al. Using pharmacists and drugstore workers as sexual healthcare givers: a qualitative study of men who have sex with men in Dar es Salaam, Tanzania. Glob Health Action. 2017;10(1):1389181.

25. Foster EK, Bandawe CR. How much do patients in Blantyre, Malawi know about antibiotics and other prescription only medicines? Malawi Med J. 2014;26(1):12-5.

26. Dillip A, Embrey M, Shekalaghe E, Ross-Degnan D, Vialle-Valentin C, Kimatta $\mathrm{S}$, et al. What motivates antibiotic dispensing in accredited drug dispensing outlets in Tanzania? A qualitative study. Antimicrob Resist Infect Control. 2015:4:30.

27. Gebretekle GB, Haile Mariam D, Abebe W, Amogne W, Tenna A, Fenta TG, et al. Opportunities and barriers to implementing antibiotic stewardship in low and middle-income countries: lessons from a mixed-methods study in a tertiary care hospital in Ethiopia. PLoS ONE. 2018;13(12):e0208447.

28. Legenza L, Barnett S, Rose W, Safdar N, Emmerling T, Peh KH, et al. Clostridium difficile infection perceptions and practices: a multicenter qualitative study in South Africa. Antimicrob Resist Infect Control. 2018;7:125.

29. Asante KP, Boamah EA, Abdulai MA, Buabeng KO, Mahama E, Dzabeng F, et al. Knowledge of antibiotic resistance and antibiotic prescription practices among prescribers in the Brong Ahafo Region of Ghana; a cross-sectional study. BMC Health Serv Res. 2017;17(1):422.

30. Pearson M, Chandler C. Knowing antmicrobial resistance in practice: a multicountry qualitative study with human and animal healthcare professionals. Glob Health Action. 2019;12(1):1599560.
31. Rout J, Brysiewicz P. Exploring the role of the ICU nurse in the antimicrobial stewardship team at a private hospital in KwaZulu-Natal, South Africa. South Afr J Crit Care (Online). 2017;33:46-50.

32. Mula CT, Human N, Middleton L. An exploration of workarounds and their perceived impact on antibiotic stewardship in the adult medical wards of a referral hospital in Malawi: a qualitative study. BMC Health Serv Res. 2019;19(1):64.

33. Tiong JJL, Loo JSE, Mai C-W. Global antimicrobial stewardship: a closer look at the formidable implementation challenges. Front Microbiol. 2016;7:1860.

34. Van Dijck C, Vlieghe E, Cox JA. Antibiotic stewardship interventions in hospitals in low-and middle-income countries: a systematic review. Bull World Health Organ. 2018;96(4):266-80.

35. Huttner B, Harbarth S, Nathwani D. Success stories of implementation of antimicrobial stewardship: a narrative review. Clin Microbiol Infect. 2014;20(10):954-62.

36. Kpokiri EE, Taylor DG, Smith FJ. Development of antimicrobial stewardship programmes in low and middle-income countries: a mixed-methods study in Nigerian Hospitals. Antibiotics (Basel). 2020;9(4):204.

37. Akpan MR, Isemin NU, Udoh AE, Ashiru-Oredope D. Implementation of antimicrobial stewardship programmes in African countries: a systematic literature review. J Glob Antimicrob Resist. 2020;22:317-24.

38. Torres NF, Chibi B, Middleton LE, Solomon VP, Mashamba-Thompson TP. Evidence of factors influencing self-medication with antibiotics in low and middle-income countries: a systematic scoping review. Public Health. 2019;168:92-101.

39. McClintock HF, Alber JM, Schrauben SJ, Mazzola CM, Wiebe DJ. Constructing a measure of health literacy in Sub-Saharan African countries. Health Promot Int. 2019;35(5):907-15.

40. Kickbusch IS. Health literacy: addressing the health and education divide. Health Promot Int. 2001;16(3):289-97.

41. Castro-Sánchez E, Chang PWS, Vila-Candel R, Escobedo AA, Holmes AH. Health literacy and infectious diseases: why does it matter? Int J Infect Dis. 2016;43:103-10.

42. Labi AK, Obeng-Nkrumah N, Bjerrum S, Aryee NAA, Ofori-Adjei YA, Yawson AE, et al. Physicians'knowledge, attitudes, and perceptions concerning antibiotic resistance: a survey in a Ghanaian tertiary care hospital. BMC Health Serv Res. 2018;18(1):126.

43. Erku DA. Antimicrobial stewardship: a cross-sectional survey assessing the perceptions and practices of community pharmacists in Ethiopia. Interdiscip Perspect Infect Dis. 2016;2016:5686752.

44. Hlashwayo DF, Sigaúque B, Bila CG. Epidemiology and antimicrobial resistance of Campylobacter spp. in animals in Sub-Saharan Africa: a systematic review. Heliyon. 2020;6(3):e03537-e.

45. Okeke IN, Babalola CP, Byarugaba DK, Djimde A, Osoniyi OR. Broadening participation in the sciences within and from Africa: purpose, challenges, and prospects. CBE Life Sci Educ. 2017;16(2):es2.
Ready to submit your research? Choose BMC and benefit from:

- fast, convenient online submission

- thorough peer review by experienced researchers in your field

- rapid publication on acceptance

- support for research data, including large and complex data types

- gold Open Access which fosters wider collaboration and increased citations

- maximum visibility for your research: over $100 \mathrm{M}$ website views per year

At BMC, research is always in progress.

Learn more biomedcentral.com/submissions 